\title{
Historia, héroes y conmemoraciones como armas de lucha política. El culto a Miguel Hidalgo en tiempos de la intervención francesa en México ${ }^{1}$
}

\section{Resumen}

El artículo muestra cómo en tiempos de la intervención francesa en México (18621867), tanto el Imperio de Maximiliano como los republicanos encabezados por Benito Juárez, reconocían en Miguel Hidalgo al Padre de la Patria, solo que cada bando -según su postura política- moldeó una interpretación distinta del personaje. Se ilustran las formas en que la forja de una memoria histórica de carácter nacional -con sus héroes y rituales celebratorios-, no solo fue parte importante para imaginar la nación y potenciar una identidad nacional, sino que también se convirtió en un tipo de arma política útil para persuadir a la población para que reconociera como legítimo a determinado proyecto de Estado.

Palabras clave: México, relato, independencia, conmemoración.

Referencia para citar este artículo: GONZÁLEZ SALINAS, Omar Fabián (2016). "Historia, héroes y conmemoraciones como armas de lucha política. El culto a Miguel Hidalgo en tiempos de la intervención francesa en México". En Anuario de Historia Regional y de las Fronteras. 21 (2). pp. 101-124.

Fecha de recepción: 30/11/2015

Fecha de aceptación: 16/02/2016

Omar Fabián González Salinas: Magíster en Historia por el Instituto de Investigaciones Históricas, Universidad Michoacana de San Nicolás de Hidalgo. Licenciado en Historia por la misma Universidad. Sus líneas de investigación versan sobre nacionalismo, nación e identidad nacional, e historia política y cultural del México contemporáneo. Correo electrónico: Omaruccio_fgs@hotmail.com.

\footnotetext{
${ }^{1}$ Este artículo fue producto de una investigación financiada por el CONACyT, la cual se convirtió en la tesis de maestría Miguel Hidalgo en los relatos de nación. Del patriotismo criollo al nacionalismo posrevolucionario. Agradezco los comentarios que Moisés Guzmán Pérez (IIH-UMSNH) y Tomás Pérez Vejo (ENAH) a una primera versión de este texto. Asimismo, a las críticas y sugerencias de los dictaminadores.
} 


\title{
History, Heroes and Commemorations as Weapons for Political Struggle. The Cult of Miguel Hidalgo in the Times of French Intervention in Mexico
}

\begin{abstract}
This article shows how, during the French intervention in Mexico (1862-1867), both the empire of Maximilian and the Republicans led by Benito Juarez, acknowledged Miguel Hidalgo as the Father of the Nation, except that each side, -according to their political position-shaped a different interpretation of the character. The ways in which the forging of a national historical memory -with its heroes and celebration rituals-, was important not only to "imagine" the nation and enhance national identity, but it also became in a kind of useful political "weapon" to persuade people to recognize a particular State project as legitimate.
\end{abstract}

Keywords: México, Narrative, Independence, Commemoration.

\section{História, heróis e comemorações como armas de luta política. O culto a Miguel Hidalgo em tempos da intervenção francesa no México}

\section{Resumo}

Apresenta a forma em que, em tempos da intervenção francesa no México (18621867), tanto o Império de Maximiliano como os republicanos liderados por Benito Juárez, reconheciam em Miguel Hidalgo ao Pai da Pátria, só que cada bandosegundo sua postura política-modelou uma interpretação diferente do personagem. São ilustradas as formas em que forjar uma memória histórica de caráter nacional -com seus heróis e rituais de celebração-, não apenas foi parte importante para "imaginar" a nação e potenciar uma identidade nacional, mas também transformouse num tipo de "arma” política útil para persuadir à população de reconhecer legítimo, determinado projeto de Estado.

Palavras chave: México, relato, independência, comemoração. 


\section{Introducción}

Después de las revoluciones atlánticas los antiguos territorios que solían conformar la monarquía católica pasaron a constituirse en Estados-nación, reconfigurando así el mapa geo-político americano. En estas nuevas entidades la nación fue posicionada como fuente de soberanía, desplazando la legitimidad por Derecho divino que justificaba el ejercicio del poder en los Estados de antiguo régimen. A partir de entonces la Modernidad política trajo consigo tres tipos de conflicto: uno ideológico sobre derechos y organización social y política, un conflicto de intereses sobre reparto de recursos, y uno identitario sobre el qué somos ${ }^{2}$.

En cuanto al conflicto identitario - que es el que aquí interesa-, este se manifestó en dos objetivos que desde entonces preocupan a todo Estado moderno: hacer visible a la nación a la que se había posicionado como sujeto de soberanía, y convencer a la población de que su identidad primordial la debían a esta. En otras palabras, se trataba de construir un relato histórico de nación y una identidad nacional.

Entender esto implica saber que si bien durante tiempos virreinales existían naciones en su acepción tradicional (grupos con mismos orígenes étnicos pero sin ningún papel político), o en realidad no existía la nación mexicana a la que se referían los artífices del Estado como la nueva fuente de soberanía, y que pretendía estar compuesta por todos los habitantes del nuevo país, quienes, supuestamente eran parte de una sola comunidad con un origen, un presente y un futuro compartidos ${ }^{3}$. Ante estas condiciones inició un proceso que los teóricos modernistas del nacionalismo han denominado como el proceso de construcción/invención de las naciones y las identidades nacionales ${ }^{4}$.

Formar una memoria histórica con pasajes épicos y mitos fundacionales se convirtió en una de las estrategias más importantes para demostrar la existencia de la nación, por ello, no es exagerada la postura de Tomás Pérez Vejo cuando afirma que la "historia nacional es para la nación una necesidad ontológica"5. Aunado a esto, el componente emotivo que conllevaba ese relato histórico, también fue pieza fundamental para potenciar un sentimiento de pertenencia en común entre la población. Pero no debe

\footnotetext{
${ }^{2}$ Para ahondar en estos planteamientos: Pérez Vejo, Tomás "La construcción de naciones como problema historiográfico: el caso del mundo hispánico”, en Historia Mexicana, vol. LIII, núm. 2, México, El Colegio de México, 2003, p. 275.

${ }^{3}$ Sobre la nación de antiguo régimen y las "mutaciones" que sufrió tras la modernidad política: Guerra, François-Xavier, "La nación moderna: nueva legitimidad y viejas identidades", en Tzintuzn. Revista de estudios históricos, núm. 36, Morelia, IIH-UMSNH, 2002, pp. 79-114; Pérez Vejo, Tomás. Elegía criolla. Una reinterpretación de las guerras de Independencia hispanoamericanas (México: Tusquets, 2010).

4 Para ahondar en esta teoría también conocida como nation building: Gellner, Ernest. Naciones y nacionalismo (México: CONACULTA/Alianza Editorial, 1991); Hobsbawm, Eric. Naciones y nacionalismos desde 1780 (Barcelona: Grijalbo, 1991); Anderson, Benedict. Comunidades imaginadas. Reflexiones sobre el origen y difusión del nacionalismo (México: FCE, 1993); Pérez Vejo, Tomás. Nación, identidad nacional y otros mitos nacionalistas (Oviedo: Ediciones Nobel, 1999).

${ }^{5}$ Pérez Vejo, Tomás. Nación, identidad nacional... p. 124.
} 
pensarse que las naciones y las identidades se reducen a términos culturales. Detrás de estos objetivos se encuentran intereses estrictamente políticos. Como se mencionó, la nación es la base de la soberanía del Estado moderno. Por otra parte, cuando los Estados moldean su propia historia, lo hacen desde una perspectiva teleológica, de tal forma que la convierten en una compilación cronológica de hechos heroicos, cuyo único final posible es la fundación del régimen político en turno ${ }^{6}$. Además, es necesario no olvidar que la identidad nacional no solo es una cuestión subjetiva, ya que esta puede alcanzar una eficacia social en la medida en que se traduce en una lealtad política hacia el Estado que se abandera como representante de la nación.

Forjar la memoria colectiva que daría vida a la nación fue una tarea realizada a través de medios materiales e inmateriales que Pierre Nora denomina lieux de mémoire (lugares de memoria), entre los que se encuentran la escritura, las imágenes, los monumentos, los rituales celebratorios, las canciones e himnos, etcétera ${ }^{7}$. De estos medios, son únicamente las fiestas cívicas conmemorativas las que aquí interesan como ejemplo para ahondar en la gestión de una memoria nacional y sus usos políticos.

Las celebraciones históricas que conforman un calendario cívico están basadas en una tarea de selección y olvido, marcando los sucesos importantes que deben conmemorar los miembros de una comunidad nacional. Son formas de socialización que incluyen constantes referencias a un pasado mítico y glorioso para reforzar el imaginario colectivo, potenciar la unidad nacional y la lealtad política. En ellas se despliegan un cúmulo de símbolos, actos ritualizados y discursos colmados de retórica patriótica con especial énfasis en las virtudes del régimen del partido, el gobernante o partido en el poder $^{8}$.

Junto a las celebraciones se encuentra el culto a los héroes nacionales, quienes generalmente encarnan el suceso conmemorado y suelen ser rememorados como

\footnotetext{
${ }^{6}$ Sobre los usos políticos de la historia, así como su relación con la forja de una nación: Ibíd., pp. 113-128; Florescano, Enrique. "Notas sobre las relaciones entre memoria y nación en la historiografía mexicana", en Historia Mexicana, vol. LIII, núm. 2, México, El Colegio de México, 2003, pp. 391-496.

${ }^{7}$ Nora, Pierre. "La aventura de Les lieux de mémoire", en Ayer. Revista de historia contemporánea, núm. 32, Madrid, Asociación de Historia Contemporánea, 1998, pp. 17-34. sobre los medios por los cuales se forma de una memoria colectiva: Burke, Peter. Formas de historia cultural (Madrid: Alianza Editorial, 2011), pp. 70-73.

${ }^{8}$ Esta definición de las celebraciones históricas bien puede amoldarse a aquellas del periodo aquí estudiado, como a las actuales. Hobsbawm, Eric. "Introducción: la invención de la tradición”, en Hobsbawm, Eric y Ranger, Terence (coords.), La invención de la tradición (Barcelona: Crítica, 2002), pp. 7-21; Santos, Ana. "El 50 aniversario de la Revolución mexicana: entre la continuidad y el agotamiento de la revolución permanente", en Pani, Érika y Rodríguez Kuri, Ariel (coords.), Centenarios. Conmemoraciones $e$ historia oficial, México, COLMEX, 2012, p. 52; Breully, John. Nacionalismo y Estado (Barcelona: Ediciones Pomares-Corredor, 1990), pp. 363-367. Sobre la organización y componentes de las fiestas de Independencia en México durante las primeras décadas del siglo XIX: Serrano Migallón, Fernando. El grito de Independencia. Historia de una pasión nacional (México: Porrúa, 1995), pp. 1-85; Costeloe, Michael. "The junta patriótica and the celebration of Independence in Mexico city, 1825-1855", en Beezley H., William y Lorey, David E. (eds.), ¡Viva Mexico! ;Viva la Independencia! Celebrations of september 16 (Wilmington: Scholary Resources, 2001), pp. 43-75.
} 
una versión mistificada de un personaje histórico. Son convertidos en una especie de líderes, ejemplos de virtudes cívicas y políticas, cuyo recuerdo se utiliza para incitar a la unión y a la defensa de la nación. Asimismo, se les emplea como medios difusores de las ideologías dominantes ${ }^{9}$. En el periodo aquí estudiado, se encuentra ante figuras heroicas propias de la modernidad, es decir, poco tenían que ver con el héroe del antiguo régimen identificado en el monarca ${ }^{10}$. Se trataba del héroe civil o el ciudadano en armas que se rebelaba contra la tiranía. Individuos a los que se les pudo elevar a este rango gracias a los nuevos símbolos de identidad inspirados por la Revolución francesa, la epopeya napoleónica, el romanticismo y el surgimiento de las naciones modernas ${ }^{11}$. En la América hispánica el culto a los héroes fue uno de los pilares para imaginar la nación, inculcar la identidad y legitimar a los gobiernos que tras las Independencias reemplazaron las estructuras de poder de la monarquía católica $^{12}$.

John Breully refiere la importancia que encierra la fusión del ritual con el culto al héroe cuando señala que el vínculo que se establece con los héroes del pasado es "[...] una garantía de que los hombres del presente serán capaces de afrontar sus desafíos como lo hicieron sus antepasados. El propio ceremonial manifiesta esta posibilidad en miniatura y ofrece la promesa de que se podrá conseguir mucho más"13.

Las conmemoraciones y el culto a figuras heroicas se consideraron como parte fundamental en la formación de una memoria colectiva, socialmente construida

\footnotetext{
${ }^{9}$ Guzmán Pérez, Moisés. “Adiós a Pelayo. La invención del héroe americano y la ruptura con la identidad hispana”, en Sánchez Andrés, Agustín; Pérez Vejo, Tomás y Landavazo, Marco Antonio (coords.), Imágenes e imaginarios sobre España en México. Siglos XIX y XX (México: Porrúa/IIH-UMSNH/CONACYT, 2007), p. 65; Crespo, José Antonio. Contra la historia oficial (Madrid: Debolsillo, 2010), p. 5.

${ }^{10}$ En el caso particular de Miguel Hidalgo, desde el tiempo de la guerra de Independencia puede percibirse cómo se le elevó al estatus de héroe. Pero en esos primeros años en que se le mitificaba, lo que existió fue una construcción heroica moderna que no rompió de tajo con la idea del héroe de antiguo régimen, por lo contrario, es un ejemplo de cómo alrededor de algunos de estos héroes próceres, hubo una mezcla de un imaginario de antiguo régimen con uno más cercano al de la modernidad política (héroes civiles a los que también se les imputaban características o elogios propios del héroe de antiguo). González Salinas, Omar Fabián. "La primera construcción mítica en torno a Miguel Hidalgo", en Revista de El Colegio de San Luis, vol. IV, núm. 8, San Luis Potosí, El Colegio de San Luis, 2015, pp. 160-190.

${ }^{11}$ Volvelle, Michel. “La Revolución francesa: ¿Matriz de la heroización moderna?”, en Chust, Manuel y Mínguez, Víctor (eds.), La construcción del héroe en España y México (1789-1847) (Valencia: Universitat de Valencia, 2003), pp. 19-29; Chust, Manuel y Mínguez, Víctor. "Presentación", en Ibíd. Mínguez, Víctor. "Héroes clásicos y reyes héroes en el antiguo régimen", en Ibid., p. 51.

${ }^{12}$ Sobre el culto a héroes nacionales en algunos países de Hispanoamérica: Earle, Rebeca. "Padres de la patria and the ancestral past: conmemorations of independeces in nineteenth-century Spanish America", en Journal of Latin American Studies, núm. 34, Cambridge, University of Cambridge, 2002, pp. 775-805; Gutiérrez Viñuales, Rodrigo. "Construyendo las identidades nacionales. Próceres e imaginario histórico en Sudamérica (siglo XIXI)”, en Chust, Manuel y Míngue Víctor (eds.), Op. cit., pp. 281-306; Rojas, Reinaldo. Venezuela: Fiesta, imaginario político y nación (San Felipe, Yaracuy: Universidad Nacional Experimental del Yaracuy, 2011); Earle, Rebecca. "Sobre héroes y tumbas: símbolos nacionales en la Hispanoamérica del siglo XIX”, en Bicentenario. Revista de historia de Chile y América, vol. VII, núm. 1, Santiago, Centro de Estudios Bicentenario, 2008, pp. 5-43.

${ }^{13}$ Breully, John, Op. cit., p. 366.
} 
Historia, héroes y conmemoraciones como armas de lucha politica. El culto a...

y reconstruida desde el presente, ello permite explicar la idea de que no existe un único significado y uso de la historia ${ }^{14}$. El pasado nacional -en la historia oficial- es constantemente amoldado a los desafíos e intereses del presente ${ }^{15}$.

Fue desde los primeros años del recién fundado país, que la conmemoración de la Independencia se convirtió en la fiesta nacional de mayor importancia. Para tal efecto se estableció el 16 y el 27 de septiembre, el comienzo y la consumación respectivamente, como las fechas de celebración. Esto es que, tanto Miguel Hidalgo (el iniciador) como Agustín de Iturbide (el consumador), eran reconocidos como Padres de la Patria sin mayores problemas. Esta situación cambió después del desastre de la guerra con los Estados Unidos (1846-1848), momento en que se fortaleció un grupo político autodenominado como conservador y que planteó que la república y el liberalismo eran caminos equivocados que solo estaban llevando a México de una catástrofe a otra.

Los conservadores proponían que la solución para fortalecer el país estaba en retomar la tradición monárquica, pues era más afín con la historia mexicana, además de creer que en ella se encontraba la clave para vivir un auge similar al que gozó la Nueva España. El proyecto político conservador fue respaldado por un discurso identitario e histórico en el que México era una nación en deuda con España, su madre patria que la educó y engrandeció. Para ellos la Independencia cobraba sentido únicamente en el reconocimiento de Iturbide como legítimo emancipador y conciliador de la nación con la herencia hispánica. Por su parte, los liberales apostaron por un proyecto político liberal, laico y republicano, respaldado por un imaginario nacional en el que se planteaba que la nación mexicana era anterior a la Conquista y había sido esclavizada por España hasta que el movimiento insurgente la liberó de esa opresión,

\footnotetext{
${ }^{14}$ Burke, Op. cit., pp. 65-85; Cannadine, David. "Contexto, representación y significado del ritual: la monarquía británica y la ‘invención de la tradición', 1820-1977”, en Hobsbawm, Eric y Ranger, Terence (coords.), Op. cit., p. 111; González Salinas, Omar Fabián. "Fiesta cívica y culto al 'Padre de la Patria' en el Estado revolucionario, 1910-1940”, en Secuencia. Revista de historia y ciencias sociales, núm. 93, México, Instituto de Investigaciones Dr. José María Luis Mora, 2015, pp. 165 y 181; Garciadiego Dantán, Javier. "La política de la historia: Las conmemoraciones de 2010”, en Pani, Erika y Rodríguez Kuri, Ariel (coords.), Op. cit., pp. 334 y 364.

${ }^{15}$ Sobre los distintos significados y usos políticos que se han dado a la fiesta de independencia mexicana y al culto a Miguel Hidalgo: Rodríguez Piña, Javier. "Conservatives contest the meaning of the Independence, 1846-1855”, en Beezley H., William y Lorey, David E. (eds.), Op cit., pp. 101-129; Cañedo Gamboa, Sergio A. Los festejos septembrinos en San Luis Potosí. Protocolo, discurso y tansformaciones, 1824-1847 (México: El Colegio de San Luis, 2001); Plasencia de la Parra, Enrique. Independencia y nacionalismo a la luz del discurso conmemorativo (1825-1867) (México: CONACULTA, 1991); Moya Gutiérrez, Arnaldo. "Los festejos cívicos septembrinos durante el Porfiriato, 1877-1910”, en Agostini, Claudia y Speckman, Elisa (eds.), Modernidad, tradición y alteridad. La ciudad de México en el cambio de siglo (XIX-XX) (México: IIH-UNAM, 2001), pp. 49-75; Landavazo, Marco Antonio. "Hidalgo: ideología e historia", en Velarde, Sofía y Dávila, Carmen Alicia (coords.), Miguel Hidalgo en la historia y el arte (Morelia: Gobierno del Estado de Michoacán, 2004), pp. 35-42; González Salinas, Omar Fabián. "Fiesta cívica y culto al 'Padre de la Patria' en el Estado revolucionario, 1910-1940”, en Secuencia..., pp. 162-183; Garciadiego, Javier, Op. cit., pp. 333-369; O’Gorman, Edmundo. "Hidalgo en la historia”, en Terán, Marta y Páez, Norma, Miguel Hidalgo: ensayos sobre el mito y el hombre (1953-2003) (México: CONACULTA/ INAH, 2004), pp. 51-61.
} 
además de dejar el camino para refundar una nueva nación más libre y más justa. Para este relato Hidalgo y la rebelión de 1810 eran símbolos fundacionales, mientras que Iturbide solo podía referir a una funesta presencia hispana. Así, después de 1848 los cultos por Hidalgo e Iturbide cobraron nuevos y contrarios significados; festejar a uno u otro se convirtió en expresión de apoyo por uno de estos dos proyectos de Estado y de nación ${ }^{16}$.

Después de promulgarse la Constitución de 1857 las diferencias entre liberales y conservadores se radicalizaron a tal grado que estalló la Guerra de Reforma (18581861). Tras el parcial triunfo liberal, los obstinados conservadores obtuvieron apoyo de Napoleón III y jugaron su última carta: impusieron una monarquía con un príncipe traído de Europa (Maximiliano de Habsburgo), apoyado por fuerzas militares de Francia. Fue el inicio de la intervención francesa y el Segundo Imperio Mexicano $(1862-1867)^{17}$.

En este nuevo contexto el ambiente político que reinaba el país continuaba dividido en dos bandos. El imperio no pudo alcanzar un consenso entre todos los mexicanos, lo que permitió que el presidente liberal Benito Juárez pudiera reunir una defensa republicana, de la cual se sabe que confrontó al proyecto conservador en las armas y en lo legal, pues además de la campaña bélica, pudo mantener un gobierno que aunque itinerante, proclamaba la legitimidad de la república sobre un imperio espurio.

Pero más allá de lo legal y militar, el enfrentamiento también se desarrolló en el campo simbólico. En las siguientes páginas se analiza cómo durante este periodo el imaginario nacional (sus conmemoraciones, mitos y héroes) fue utilizado como arma política empleada para defender los dos proyectos de Estado en pugna. Si bien es cierto que cuando los conservadores instauraron el Imperio de Maximiliano lo hicieron pensando que México debía volver a la monarquía y a retomar la herencia hispánica, no contaban con que el emperador tendría mayor empatía por el proyecto político y de nación de los liberales. Incluso Maximiliano decidió poner fin a la fiesta dedicada a Iturbide y dedicar la celebración de Independencia a Miguel Hidalgo. Con ello, aparentemente quedaban zanjadas las diferencias identitarias entre ambos bandos políticos; no obstante, la hipótesis que interesa sustentar aquí plantea que aunque el

\footnotetext{
${ }^{16}$ Sobre los distintos significados políticos que se construyeron en torno al culto a Hidalgo y a Iturbide durante la primera mitad del siglo XIX: Pérez Vejo, Tomás. "Hidalgo contra Iturbide: la polémica sobre el significado de la guerra de Independencia en el México anterior a la República Restaurada”, en Guzmán Pérez, Moisés (coord.), Guerra e imaginarios politicos en la época de las Independencias (Morelia: IIH/ UMSNH, 2007), pp. 193-223. Para un estudio más detallado sobre los proyectos identitarios de liberales y conservadores: Pérez Vejo, Tomás. España en el debate público mexicano, 1836-1867. Aportaciones para una historia de la nación (México: El Colegio de México/ENAH/INAH, 2008).

${ }^{17}$ Aunque la historiografía tradicional considera este episodio como una de las más grandes traiciones nacionales, se debe considerar que los conservadores también eran patriotas que buscaban cómo solucionar los problemas que aquejaban al país, tan solo difirieron de los liberales en cuanto a qué camino se debía seguir para alcanzar el progreso y estabilidad política. Pani, Erika. Para mexicanizar el Segundo Imperio. El imaginario político de los imperialistas (México: El Colegio de México/Instituto de investigaciones Dr. José María Luis Mora, 2001).
} 
Historia, héroes y conmemoraciones como armas de lucha politica. El culto a...

Imperio y los republicanos ya rendían honores a un mismo Padre de la Patria y en una misma fecha, ambos lo dotaron de distinto sentido y lo emplearon con diferentes fines políticos. Lo relevante de dicho proceso no radica en saber a qué personaje se encumbró en el santoral cívico, sino en explicar cómo se utilizaron los rituales celebratorios y el culto al héroe como estrategia política, donde la rememoración de la historia poco tenía que ver con construir una imagen fiel del pasado y sí mucha importancia para consolidar un solo proyecto de Estado-nación en el presente desde el cual se rememoraba.

Como última precisión se menciona que existen estudios que contradicen la idea de que la formación de la identidad y la cultura nacional sean absolutas imposiciones desde arriba, lideradas por elites políticas e intelectuales y dirigidas hacia el pueblo bajo, quienes supuestamente no tienen idea alguna del nacionalismo por tratarse de sectores sociales que no han sido impactados por la industrialización y por carecer de todo interés político relacionado con la nación ${ }^{18}$. Eric Hobsbawm precisaba que no se debe pensar que lo que el Estado pregona en términos de nación e identidad nacional, es aceptado y asimilado por toda la sociedad, pues esta también puede tener sus propios significados para muchas nociones identitarias ${ }^{19}$. Cada vez más se muestra la necesidad de sacar el microscopio y analizar cómo en los pueblos de las periferias o los barrios bajos de las ciudades los proyectos de Estado-nación eran -y son- discutidos o apropiados por los grupos subalternos. En muchas ocasiones la cultura nacional suele ser un producto resultante no de una imposición, sino de un complejo proceso de negociación, conflicto y resistencia entre las elites políticas y el resto de la sociedad ${ }^{20}$.

Si bien este artículo únicamente se enfoca en la apropiación y uso que las elites políticas daban al imaginario nacional, no se pretende plantear que el discurso diseñado desde arriba haya tenido un éxito total en toda la población. No se descarta

\footnotetext{
${ }^{18}$ Ernest Gellner es quien otorga mayor importancia a la sociedad burguesa industrializada como el elemento determinante para que surja el nacionalismo. Gellner, Ernest. Naciones y nacionalismo...

${ }^{19}$ Hobsbawm precisaba que la invención de las naciones se desarrolla en un proceso de verticalidad que se forja desde arriba, entre los representantes del gobierno y sus intelectuales, y se dirige hacia abajo, donde se ubica el grueso de la población. Si se toma este modelo habría que pensar que desde abajo también se gestan resistencias y presiones que obligan a que la cultura nacional también sea formada por los embates que van de abajo hacia arriba. Hobsbawm, Eric. Naciones y nacionalismo..., pp. 18-20.

${ }^{20}$ Sobre esta perspectiva: Mallón, Florencia. Campesinos y nación. La construcción de México y Perú poscoloniales (México: CIESAS/COLMICH/COLSAN, 2003); Vaughan, Mary Kay. "The construction of the patriotic festival in Tecamachalco, Puebla, 1900-1946”, en Beezley, H. William, English Martin, Cheryl y French, William E. (eds), Rituals of rule, rituals of resistence. Public celebrations and popular culture in Mexico (Wilmington: Scholary Resources, 1999), pp. 213-245). Sobre los problemas de enfoque y de fuentes que puede tener esta tendencia historiográfica: Falcón, Romana. "Los trozos de la nación. Retos en el estudio de la formación de la nación mexicana", en Oikión Solano, Verónica (ed.), Historia, nación y región (Zamora: El Colegio de Michoacán, 2007), pp. 537-571.
} 
la posibilidad de que el pueblo bajo también haya tenido su propia idea de la historia nacional, y ello lo hayan empleado para defender sus comunidades, su cultura o sus propias concepciones de soberanía y territorio nacional ${ }^{21}$.

\section{EI Imaginario nacional republicano y el imaginario nacional del Segundo Imperio}

Con la invasión francesa, los liberales convencidos del republicanismo como única forma de gobierno posible, retomaron la idea de la existencia de una nación liberada por Hidalgo en 1810 y que debían oponerse a toda intervención extranjera en el país. Por su parte, los defensores del Imperio apelaron a una propaganda nacionalista para dotar a la nueva monarquía de una imagen nacional mexicana. En este periodo se definieron lo que se denomina como un imaginario nacional republicano y un imaginario nacional del Segundo Imperio. El primero de ellos fue parte de la defensa del liberalismo y la república como legítima forma de gobierno. El imaginario del Segundo Imperio nació por la necesidad de legitimar al gobierno del recién llegado emperador europeo, Maximiliano.

Una característica que distinguió al imaginario nacional de los opositores al Segundo Imperio fue la influencia recibida del republicanismo clásico; aspecto que David Brading señala como una de las particularidades de la retórica patriótica de estos liberales, quienes identificaron la forma de gobierno republicano como expresión de la nación ${ }^{22}$. Entre estos liberales el festejo de la Independencia y la retórica nacionalista funcionaban como trincheras desde las cuales se definió el republicanismo no solo como forma de gobierno, también en sus principios filosóficos: construcción de una sociedad con ciudadanos virtuosos, libertad delineada por las leyes y la fabricación de un imaginario patriótico inspirado en la defensa de la República ${ }^{23}$.

\footnotetext{
${ }^{21}$ Para el caso de la fiesta de Independencia y el culto patriótico a Hidalgo, otros estudios enfocados en distintos periodos y espacios han avanzado en cómo las clases populares se han apropiado y resignificado estos dos importantes elementos del imaginario nacional mexicano. Lacy, Elaine C. "The 1921 Centennial celebration of Mexico's Independence. State building and popular negotiation”, en Beezley H., William y Lorey, David E. (eds.), Op. cit., pp. 199-232; Uzeta, Jorge. "Los usos de Hidalgo", en Relaciones. Estudios de historia y sociedad, vol. XXVII, núm. 106, Zamora, El Colegio de Michoacán, 2006, pp. 57-80; Ríos Gordillo, Carlos Alberto. "La memoria asediada. La disputa por el presente en la conmemoración del bicentenario", en Secuencia. Revista de historia y ciencias sociales, núm. 87, México, Instituto Mora, 2013, pp. 177-204; Moreno Elizondo, José Elizondo. El nacimiento de la tragedia. Criminalidad, desorden público y protesta popular en las fiestas de Independencia. Ciudad de México 1887-1900 (México: Instituto Mora, 2015).

${ }^{22}$ Brading, David. Mito y profecía en la historia (México: FCE, 2010), pp. 79-125.

${ }^{23}$ Sobre los aspectos filosóficos del republicanismo: Bobbio, Norberto y Viroli, Maurizio. Diálogo en torno a la república (México: Tusquets, 2002) pp. 9-34; Barrón, Luis. "Republicanismo, liberalismo y conflicto ideológico en la primera mitad del siglo XIX en América Latina”, en Aguilar, José Antonio y Rojas, Rafael (coords.), El republicanismo en Hispanoamérica. Ensayos de historia intelectual y política (México: FCE/ CIDE, 2002), pp. 118-137.
} 
Esto es posible observarlo en personajes como Juan Díaz Covarrubias, quien utilizó un discurso conmemorativo de la Independencia para defender la república como la forma de gobierno más conveniente para el país. Hizo un elogio de las virtudes que el republicanismo podía implantar en la sociedad: reclamó respeto por las autoridades y obediencia a la Ley. Habló de la necesidad de fomentar una sociedad virtuosa que pudiera buscar el bien común dentro de la república:

[...] ¿Cuál es la forma de gobierno que más conviene a México? La República, la verdadera República, que es justicia, la fraternidad, la garantía, el apostolado, los mandamientos de Dios [...] Que en la formación del gobierno haya acierto para elegir funcionarios, prefiriendo a la honradez y al talento [...] Que el gobierno cuide minuciosamente de la educación del pueblo y de los indios [...] Que los legisladores y diputados en vez de decir hermosas palabras, velen por la felicidad o conserven los intereses del pueblo que los envía al Congreso $[\ldots]^{24}$.

En plena resistencia ante el Segundo Imperio la actitud de los liberales republicanos se encuadra en lo que Ernest Gellner denomina como una de las actitudes más emotivas del nacionalismo: el deseo de que los representantes del Estado pertenezcan a una misma cultura nacional, es decir, que el gobierno no esté en manos de extranjeros ${ }^{25}$. Ignacio Manuel Altamirano, por ejemplo, ligó el sentir nacionalista con el republicanismo y no dudó en incitar a la población a luchar con fervor patriótico en contra del Imperio. ¡Guerra, guerra al imperio y victoria por la república!, exclamó Altamirano en un discurso durante un festejo septembrino ${ }^{26}$.

Más tarde, los más notables liberales expresaron su anhelo de construir una comunidad nacional a través de distintos medios: Ignacio Ramírez, el Nigromante, se pronunció a favor de que el gobierno tuviera total control de las fiestas patrias, las cuales solían ser organizadas por juntas de ciudadanos. Con esta iniciativa el gobierno liberal podía aspirar a un monopolio del sentido de la historia y sus celebraciones. Se pensó también en manejar la educación pública para convertirla en el medio para que las jóvenes generaciones aprendieran "sus deberes sagrados y sus derechos inviolables" ${ }^{27}$, pues solo así se podían formar los ciudadanos "leales y progresistas que la nación necesitaba" ${ }^{28}$. Guillermo Prieto reflexionaba sobre la necesidad de crear una literatura

\footnotetext{
24 "Discurso cívico pronunciado en la ciudad de Tlalpan por la noche del 15 de septiembre de 1857". Consultado en Serrano Migallón, Fernando. La Independencia vista por la Reforma (México: CONACULTA, 2009), pp. 34-35.

${ }^{25}$ Gellner, Ernest. Nacionalismo (Barcelona: Ediciones Destino, 1997), p. 22.

26 "Guerra al imperio y victoria por la República. discurso en la ciudad de Tixtla, Guerrero, el 16 de septiembre de 1866”. Consultado en Serrano Migallón, Fernando, La Independencia ..., p. 98.

${ }^{27}$ Ramírez, Ignacio. Obras Completas de Ignacio Ramírez (El Nigromante), t. IV (México: Centro de Investigaciones Científicas Jorge T. Tamayo, 1987), pp. 295-296; Altamirano, Ignacio Manuel. Páginas intimas de Ignacio Manuel Altamirano (México: Gobierno del Estado de Guerrero, 1996), pp. 6 y 9; Prieto, Guillermo. Atentamente... Guillermo Prieto (México: Promexa Editores, 1979), pp. 224-228.

${ }^{28}$ Ibid.
} 
nacional, señalaba que aún "no había costumbres verdaderamente nacionales"29 e insistía en la necesidad de que el gobierno supiera organizarse, puesta hasta entonces solo había demostrado no tener idea en cómo formar un pueblo ${ }^{30}$.

De manera paralela, los ideólogos del Segundo Imperio delinearon su propio imaginario nacional con miras a sustentar la nueva monarquía y ganar lealtad hacia el emperador. Se intentó mexicanizar al Imperio, construir un Estado en términos políticos y “[...] paradójicamente el gobierno del austriaco, supuestamente usurpador y antinacional, desplegó un vigoroso programa cultural de claro y consciente cariz nacionalista" ${ }^{\text {" }}$. Gracias a la facilidad de medios y recursos, se pudo definir y difundir un aparato propagandístico nacionalista más acabado que el de la resistencia republicana.

En este esfuerzo nacionalista la pareja imperial hizo lo propio al tomar la determinación de no hablar más que español, comer platillos mexicanos aunque los hicieran llorar, vestían y montaban a caballo a la mexicana. Maximiliano usaba trajes de charro, la emperatriz optó por cambiar su nombre Charlotte por una versión castellana: Carlota, y en una ocasión posó para un retrato en el que quiso ser representada como la patria mexicana, vistiendo una túnica blanca con un tocado tricolor ${ }^{32}$.

Los representantes del Segundo Imperio recurrieron a la historia y a los símbolos mexicanos. Se empleó la bandera tricolor y el escudo nacional mantuvo el ícono del águila posada en un nopal devorando una serpiente; aunque se le tuvo que añadir la corona imperial que aludía a la monarquía. El pasado prehispánico se tomó como una rica fuente para crear una mitología nacional. En 1865 se decretó la creación de un Museo Público de Historia Natural Arqueología e Historia para resguardar restos arqueológicos. Incluso, se propuso regresar a México el penacho de Moctezuma. En sus discursos, Maximiliano exaltaba el pasado precolombino, se hacía llamar el salvador del continente del Anáhuac, mandaba publicar proclamas en lengua náhuatl y en ellas se autonombraba como el nuevo huei tlatoani, mientras que se refería a los mexicanos como los nietos de Moctezuma ${ }^{33}$. El emperador buscó hacerse un lugar en una imaginaria genealogía imperial mexicana que se remontaba al tiempo de los antiguos huei-tlatoanis, de los que ahora él se proclamaba heredero.

\footnotetext{
${ }^{29}$ Ibid.

${ }^{30}$ Ibid.

${ }^{31}$ Pani, Erika. Para mexicanizar..., p. 197; Pani, Erika. "Cultura nacional, cannon español”, en Lida, Clara E., España y el Imperio de Maximiliano (México: El Colegio de México, 1999), p. 218.

32 Pani, Erika. "El proyecto de Estado de Maximiliano a través de la vida cortesana y del ceremonial público", en Historia Mexicana, vol. XLV, núm. 2, México, El Colegio de México, 1995, p. 442; Beezley, William H. La identidad nacional mexicana. La memoria, la insinuación y la cultura popular en el siglo XIX (México: COLEF/COLSAN/COLMICH, 2008), p. 18.

${ }^{33}$ Pani, Erika. “'Verdaderas figuras de Cooper' o ¿'Pobres inditos infelices’? La política indigenista de Maximiliano”, en Historia Mexicana, vol. XLVII, núm. 3, México, El Colegio de México, 1998, pp. 574-577; Earle, Rebeca. "Padres de la patria and the ancestral past: conmemorations of independeces in nineteenth-century Spanish America", en Journal of Latin..., p. 785.
} 
Mediante monumentos públicos y otras manifestaciones artísticas, el Imperio también pudo hacer visible su interpretación histórica. Se mandaron pintar seis frescos con temas prehispánicos y en otra ocasión se compró un cuadro que representaba la mítica fundación de México ${ }^{34}$. Destaca la pretensión de retomar y concretar un monumento a la Independencia en la capital del país. Se ordenó levantar esculturas dedicadas a Morelos y a Vicente Guerrero, así como un sarcófago para Iturbide. No obstante, algunos de estos proyectos no lograron concretarse ${ }^{35}$.

Se establecieron fiestas nacionales como el mencionado 16 de septiembre en honor al Día de la Independencia, o el 12 de diciembre, Día de la Virgen de Guadalupe. Con ello el Imperio no solo exaltaba el pasado, también recurría a la devoción guadalupana de manera inteligente, pues dicho culto gozaba de enorme popularidad en el país y era una excelente estrategia para ganarse el afecto de gran parte de la población. Entre los intereses del emperador se encontraba el difundir la idea de que su gobierno era para todo el pueblo y no para unos cuantos; para ello se estipuló que estas fiestas fueran de carácter popular, para lo cual se incluyeron diversiones y desfiles ${ }^{36}$.

El Segundo Imperio se inclinó por un imaginario nacional distinto al que hasta entonces habían diseñado los conservadores, y se acercó más al que enarbolaban los liberales (exaltación del pasado prehispánico, condena del virreinato y culto por Hidalgo y los primeros insurgentes). Parecía que había mayor acuerdo en cuanto al tema identitario, pero con la enorme diferencia de que unos emplearon ese relato de nación para defender un proyecto de república, y otros para legitimar la nueva monarquía.

\section{Un mismo héroe para la República y el Imperio}

En medio de esta guerra de símbolos y de discursos movilizadores, cada bando político hizo una particular apropiación de la figura de Miguel Hidalgo, el más importante de los héroes en la mitología nacional de los dos grupos. Los liberales se consideraron como los herederos de la insurgencia de 1810 y difundieron una campaña propagandística de cuño nacionalista que interpretaba la resistencia republicana y la lucha contra el Imperio, como obra patriótica que representaba una Segunda Independencia.

La unión entre el proyecto liberal y el culto a Hidalgo ya se había presentado con fuerza durante las diferencias iniciadas con el partido conservador a finales de la década de 1840. En el campo de la iconografía, destacó el hecho de que la primera serie de timbres postales de México hayan sido impresos con la imagen del Héroe de

\footnotetext{
${ }^{34}$ Pani, Erika, “'Verdaderas figuras de Cooper' o ¿'Pobres inditos infelices’? La política indigenista de Maximiliano", en Historia Mexicana..., p. 574.

${ }_{35}$ Acevedo, Esther. "Las imágenes de la historia (1863-1867). Memoria y destrucción", en Memoria, núm. 3, 1991, pp. 27-41. Sobre algunos proyectos de rescate, exhibición y representación plástica del pasado mexicano y sus personajes: la selección de notas hemerográficas compiladas en Acevedo, Esther. "Documentación de la época del Segundo Imperio", en Memoria, núm. 3, 1991, pp. 43-57.

${ }^{36}$ Pani, Erika. "El proyecto de Estado de Maximiliano a través de la vida cortesana y del ceremonial público”, en Historia Mexicana ..., pp. 446-449.
} 
Dolores. En 1861 el gobierno de Juárez mandó emitir una segunda serie en los que nuevamente se imprimió al personaje. ${ }^{37}$ Dentro de la pintura de historia, el Héroe de Dolores también tuvo su protagonismo. En 1859 Felipe Castro pintó el cuadro La tumba de Hidalgo; una obra en la que presentaba un idealizado sepulcro para el Padre de la Patria, mismo que era rodeado por distintos elementos del imaginario nacional de los liberales. La pintura se exhibió en la Sociedad Jalisciense de Bellas Artes, una institución, cuya producción plástica ayudó a moldear un programa iconográfico característico del proyecto liberal. ${ }^{38}$

De suma importancia resulta la declaración de Ignacio Ramírez, quien señaló que los mexicanos únicamente "[...] venimos del pueblo de Dolores, descendemos de Hidalgo y nacimos luchando como nuestro padre, por los símbolos de la emancipación y como él luchando por la santa causa desapareceremos sobre la tierra" ${ }^{" 39}$. Con ello el Nigromante ubicaba al grito de Dolores como el origen de la nación liberal.

Los republicanos siguieron creando vínculos de unión entre su lucha y la de 1810 , llegando al punto en que convirtieron al Héroe de Dolores en un predecesor directo de las ideas de la Reforma liberal y precursor del republicanismo en México. Ignacio Ramírez sostenía que "[...] Hidalgo, con solo declarar la Independencia de la patria, proclamó, acaso sin saberlo, la República, la Federación, la tolerancia de cultos y todas nuestras leyes de Reforma" $"$. A través del discurso conmemorativo de la Independencia, el Nigromante declaraba: “iLibertad, reforma! Hidalgo las repetirá desde el cielo" ${ }^{41}$.

Ese Hidalgo descrito por los liberales no se parecía mucho, quizás en nada, al párroco de Dolores que había encabezado el levantamiento de 1810, pues en realidad nunca plasmó un proyecto para instaurar una república y mucho menos fue partidario de la libertad de cultos. Hidalgo se levantó en armas, entre otros motivos, para defender la religión católica, además de que tomó como estandarte a la virgen de Guadalupe. Pero se trataba de un héroe reconstruido desde los intereses políticos de aquellos que apelaban a su memoria. El resultado fue un desfase entre el personaje del pasado y el que se reconfiguraba a partir del presente. Era la historia oficial, el mito y el culto al héroe en su más clara función: legitimar, más no explicar, por lo cual, la objetividad pasó a un segundo plano.

\footnotetext{
${ }^{37}$ Sobre la historia y las imágenes de los timbres postales en México: (Sin datos). Tres siglos de filatelia en México (México: AMEXFIL, 2006).

${ }^{38}$ Ramírez, Fausto. "Miguel Hidalgo: de sacerdote a patriarca”, en Azcárate Esquinca, Bernardo (coord.), El éxodo mexicano, los héroes en la mirada del arte (México: UNAM/MUNAL, 2010), p. 251.

39 "Discurso cívico pronunciado el 16 de septiembre de 1861, en la Alameda de México, en memoria de la proclamación de la Independencia”. Consultado en Serrano Migallón, Fernando, La Independencia..., pp. 47-54.

${ }^{40}$ Ramírez, Ignacio, Op. cit., p. 39.

41 "Discurso cívico pronunciado el 16 de septiembre de 1861, en la Alameda de México, en memoria de la proclamación de la Independencia”. Consultado en Serrano Migallón, Fernando, La Independencia...., p. 55 .
} 
Por su parte, en 1863 cuando el presidente Benito Juárez se dirigía al norte del país con su gobierno itinerante, a su paso por el pueblo de Dolores emitió un decreto en el que se ordenaba que la villa tomara al rango de ciudad; se estipuló que en la plaza principal se levantara un monumento dedicado a Hidalgo y se nacionalizó la que había sido la casa del héroe en dicha localidad ${ }^{42}$. El antiguo hogar del párroco se transformó en monumento nacional y con la llegada de la intervención francesa, los republicanos lo convirtieron en una especie de sitio de peregrinación patriótica donde el culto a Hidalgo comenzó a utilizarse para convocar a la guerra contra las tropas del Imperio.

En el libro de visitas del recién creado museo, existen mensajes que denotan cómo hasta allá acudían los partidarios de la república para pedirle al héroe que les diera fuerzas para combatir al ejército de ocupación: "[...] siguiendo el noble ejemplo que nos dio el inmortal Hidalgo [...] llenos de los más gratos recuerdos en memoria de nuestro héroe y libertador del yugo español, y nosotros humildes soldados del pueblo, juramos imitarlo para liberar a nuestros hijos de las cadenas del déspota francés" ${ }^{43}$. Y no solo militares y los políticos vieron en él un aliciente para combatir a los invasores, parte de la población también lo tomó como un símbolo contra el intervencionismo francés ${ }^{44}$.

Como el festejo de la Independencia se había convertido en un espacio propicio de movilización militar, los líderes de la resistencia republicana se esforzaban en celebrar la fecha aunque fuera de manera modesta y en poblaciones pequeñas o en campamentos militares. Así ocurrió en el poblado de Tixtla, donde Ignacio Manuel Altamirano aprovechó la conmemoración de la Independencia para declarar que "[...] mientras que un solo francés armado pise el territorio nacional, mientras que un solo traidor se atreva a invocar en la tierra de Hidalgo otra cosa que no sea la República $[\ldots]$ la palabra de los que hablan al pueblo debe ser la guerra $[\ldots]^{\prime 45}$.

Con el recuerdo de los héroes Altamirano incitaba a luchar contra el Imperio, pues argumentaba que de esa forma Hidalgo, Padre de la Patria, y Vicente Guerrero, Padre del Sur, estarían orgullosos de los mexicanos ${ }^{46}$. Por su parte, Ignacio Ramírez proclamaba que Hidalgo desde su sepulcro, al sentir los pasos de los franceses le gritó a los mexicanos "¡Odio a los invasores!" 47 .

\footnotetext{
42 "Expediente relativo al monumento conmemorativo que debe erigirse en Dolores Hidalgo al primer caudillo de la Independencia". Consultado en Hernández y Dávalos, J. E. Colección de documentos para la historia de la guerra de Independencia de México de 1808 a 1821, t. II (Liechtenstein: Kraus Reprint, 1968), pp. 611-612.

${ }^{43}$ Álbum de Hidalgo (México: UMSNH/Centro de Estudios sobre la Cultura Nicolaita, 2000), pp. 26 y 77.

${ }^{44}$ Ibid.

45 "Guerra al imperio y victoria por la República. discurso en la ciudad de Tixtla, Guerrero, el 16 de septiembre de 1866”. Consultado en Serrano Migallón, Fernando, La Independencia ..., p. 79.

${ }^{46}$ Ibid., p. 98.

${ }^{47}$ Ramírez, Ignacio, Op. cit., p. 57.
} 
Los republicanos “[...] reforzaron en su discurso la imagen de una línea de continuidad entre el enfrentamiento Hidalgo/realistas juaristas/seguidores de Maximiliano"48. Altamirano rememoraba la Independencia y al Héroe de Dolores, y aprovechaba la retórica patriótica para elogiar a Juárez, a quien le reconoció la entereza de oponerse al tirano francés, motivo por el cual, decía Altamirano, ganaría el título de "segundo padre de la Independencia mexicana"49.

En cuanto a los adeptos al Segundo Imperio, estos también recurrieron al culto por los héroes mexicanos. Maximiliano tuvo un especial acercamiento hacia la figura de Hidalgo. Esto se reflejó en su decisión por trasladarse al poblado de Dolores para encabezar su primer festejo de la Independencia el día 16 de septiembre de 1864. Allí pronunció un discurso en el que hizo un ataque al pasado virreinal -al que calificó como momento de esclavitud y despotismo-y resaltó la lucha iniciada en 1810. Las crónicas del evento relatan que después de los vivas a la Independencia siguieron otras para la pareja imperial y al mismo Napoleón III $^{50}$. Desde la organización y con la actitud esperada del público asistente, se lograba adecuar la fiesta patriótica como ritual político que legitimaba al Imperio.

Maximiliano no solo contrarió al partido conservador con su decidido culto por Hidalgo, incluso llegó al punto de decretar la desaparición de la fiesta dedicada a Iturbide, el héroe de los conservadores y símbolo del imaginario nacional hispanófilo que estos defendían. Quedó estipulado que se suprimía el festejo del 27 de septiembre y así, oficialmente la conmemoración del grito de Hidalgo se convirtió en la única fiesta nacional de Independencia ${ }^{51}$.

Esta aceptación del cura de Dolores fue reproducida por varios mexicanos adeptos al Imperio. Miguel Miramón, quien fue uno de los principales militares que apoyó a Maximiliano en su paso por Dolores reconoció en Hidalgo al primer héroe de nuestra Independencia. También algunos franceses que vinieron con el emperador mostraron su respeto por el personaje, al que se referían como el gran Hidalgo ${ }^{52}$. Hubo personas que en su visita al Museo Casa de Hidalgo dejaron comentarios con muestras de lealtad a Maximiliano y peticiones al Padre de la Patria para que diera protección y buena fortuna al Imperio ${ }^{53}$.

\footnotetext{
${ }^{48}$ Pérez Vejo, Tomás. "Hidalgo contra Iturbide: la polémica sobre el significado de la guerra de Independencia en el México anterior a la República Restaurada”, en Guzmán Pérez, Moisés (coord.), Guerra e imaginarios políticos..., p. 214.

49 "Guerra al imperio y victoria por la República. discurso en la ciudad de Tixtla, Guerrero, el 16 de septiembre de 1866”. Consultado en Serrano Migallón, Fernando, La Independencia ..., p. 93.

50 "El emperador en Dolores", La sociedad, México, 17 de septiembre de 1864; "Continuación del diario de viaje de S. M. el emperador”, La sociedad, México, 28 de septiembre de 1864.

${ }^{51}$ Plasencia de la Parra, Enrique, Op. cit., p. 116; Pérez Vejo, Tomás. "Hidalgo contra Iturbide: la polémica sobre el significado de la guerra de independencia en el México anterior a la República Restaurada”, en Guzmán Pérez, Moisés (coord.), Guerra e imaginarios políticos..., p. 214.

${ }^{52}$ Álbum de Hidalgo..., pp. 43, 44 y 75.

${ }^{53}$ Los comentarios pueden consultarse en Ibid.
} 
Así como los republicanos sostenían su proyecto político con un discurso histórico en el que se hacían ver como herederos de Hidalgo y defensores de la Independencia, los partidarios de Maximiliano hicieron lo propio al tender un puente simbólico que unía al Imperio con la insurgencia de 1810. La prensa conservadora catalogó a Maximiliano como un príncipe que antes había sido extranjero, pero que ahora gobernaba México por adopción del Anáhuac y que gracias a su benevolencia y a la generosidad de la Francia, la nación mexicana podía conservar su Independencia. Hubo quienes pensaban que Hidalgo y los primeros insurgentes hubiesen apoyado a Maximiliano, pues mencionaban que lejos de proponer un cambio de gobierno, aclamaron al monarca Fernando VII ${ }^{54}$.

Con el giro que dio Maximiliano al imaginario conservador, los adeptos a este partido no solo tuvieron que aceptar al Héroe de Dolores y buscar cómo vincularse con él; sino que otra de sus estrategias se enfocó en pregonar que era una aberración que Juárez y los jefes liberales se compraran con Hidalgo y los jefes de la Independencia. Sus argumentos se centraron en señalar que "nada tenían en común los cabecillas liberales, enemigos de Dios y de su Iglesia" 55 , con los insurgentes de 1810, pues "la Independencia había sido inspirada por 'la más ardiente fe cristiana"'56.

Entre el repertorio iconográfico empleado como soporte ideológico del Imperio, resalta el conjunto de pinturas que fueron encargadas para decorar el Palacio Imperial de México y que estuvieron dedicadas a representar a los caudillos de la Independencia. A decir de Fausto Ramírez, se trataba de un programa iconográfico de visión incluyente y conciliatoria con el pasado mexicano. En cuanto al retrato dedicado a Hidalgo, este fue realizado en 1865 por Joaquín Ramírez, quien pintó al caudillo en su estudio, momento en que, después de haber pasado largas horas plasmando en papel sus más profundos pensamientos revolucionarios, decidía incorporarse de su silla para en seguida salir a convocar a su pueblo para conquistar la libertad (tema aparentemente inspirado en la pintura Napoleón en su gabinete, de Jacques Louis David en 1812). La obra planteaba la idea de que Hidalgo no solo había llamado a las armas contra España, sino que también era el legítimo ideólogo de la Independencia. El héroe, a diferencia de otros personajes del mismo programa iconográfico, no fue representado con atributos militares; en él se buscó destacar sus capacidades jurídicas, legislativas y reflexivas, pero activo al mismo tiempo. Gracias a Maximiliano México tuvo la imagen del Héroe de Dolores más reproducida y que terminó por sentar un canon iconográfico para representarlo ${ }^{57}$.

\footnotetext{
54 "Fiestas patrióticas en Toluca", La Sociedad, México, 14 de septiembre de 1864; "Discurso pronunciado en el gran Teatro Imperial en la noche del 15 de septiembre de 1864 por Juan Nepomuceno Pastor", La Sociedad, México, 17 de septiembre de 1864.

${ }^{55}$ Pérez Vejo, Tomás, "Hidalgo contra Iturbide: la polémica sobre el significado de la guerra de Independencia en el México anterior a la República Restaurada”, en Guzmán Pérez, Moisés (coord.), Guerra e imaginarios politicos..., pp. 214-215.

${ }^{56}$ Ibid.

${ }^{57}$ Ramírez, Fausto. "Hidalgo en su estudio, la ardua construcción de la imagen del Pater Patriae mexicano", en Chust, Manuel y Mínguez, Víctor (eds.), Op. cit., pp. 204-209; Rodríguez Moya, Inmaculada. "La galería de héroes de Maximiliano: hacia una reconciliación del imaginario mexicano", en Mínguez, Víctor y Chut, Manuel (eds.), El imperio sublevado (Madrid: CSIC, 2004), pp. 305-323.
} 
No obstante, dentro de esta campaña nacionalista en algunos poblados se rechazó el aparato nacionalista del Imperio. Fue el caso de San Ángel, población cercana a la capital del país, donde un grupo de personas con el afán de mostrarse contrarios al gobierno de Maximiliano, se negaron a participar en las celebraciones de Independencia promovidas por el gobierno imperial ${ }^{58}$.

Incluso también en el grupo conservador hubo desacuerdos con la nación imaginada por el Imperio. Fue el caso de José María Gutiérrez Estrada, quien renunció a su papel de enviado extraordinario y ministro plenipotenciario de México en Roma, argumentó su desacuerdo por la política liberal del emperador y añadió el disgusto que le causó el discurso de Maximiliano en Dolores y la derogación de la festividad del 27 de septiembre (la dedicada a Agustín de Iturbide), acciones que, según Gutiérrez Estrada, iban en contra del verdadero aniversario de la Independencia ${ }^{59}$.

Finalmente, Napoleón III decidió retirar sus tropas de México debido a los conflictos bélicos en Europa y las presiones que comenzó a ejercer el gobierno de Estados Unidos que recién salía de su guerra civil y reivindicaba la no intervención europea en América. Maximiliano perdió su más grande bastión militar, y la resistencia republicana comenzó a ganar terreno hasta que en 1867 lograron derrocar al Imperio. Es digno de mencionar que antes de ser ejecutado, el emperador se dio tiempo para mostrar que su apego por México y su historia no era solo una maniquea estrategia propagandística, sino un genuino sentimiento de amor por la patria que gobernó; ante el pelotón de fusilamiento exclamó: “[...] voy a morir por una causa justa, la de la Independencia y libertad de México ¡Que mi sangre selle las desgracias de mi nueva patriai ¡Viva Méxicoi" ${ }^{\prime 60}$.

\section{Conclusiones}

Este estudio muestra cómo durante el turbulento siglo XIX hispanoamericano los usos de la historia, del culto a los héroes y de las celebraciones patrióticas, no solo sirvieron para forjar una memoria colectiva, pues también se les convirtió en un tipo de armas políticas útiles para respaldar los diferentes procesos de construcción del Estado nacional. En la coyuntura aquí abordada, para los liberales el festejo de la Independencia no solo representó la oportunidad de imaginar un pasado nacional, también sirvió para llamar a las armas y defender la República como forma de gobierno. La figura de Hidalgo tomó importancia como el héroe evocado para respaldar los ideales de Juárez y sus seguidores. Mientras tanto, para los adeptos al Segundo Imperio, imaginar un relato de nación mexicano y vincularse a él, fue una necesidad de primer orden para legitimar el régimen. En dicha tarea, celebrar la Independencia e incentivar al culto por el Héroe de Dolores fueron piezas fundamentales. Para ellos, estos símbolos no

\footnotetext{
${ }^{58}$ Zárate Toscano, Verónica. "San Angel as the site of national festivals in the 1860's", en Beezley, William H., y Lorey, David E., (eds.), Op. cit., p. 99.

${ }^{59}$ Archivo Centro de Estudios Históricos de México (CEHM), Fondo IX-1, Legajo 478, Carpeta 4-8, Doc.

1. ("Carta de Francisco de Arrangoiz").

${ }^{60}$ Citado en Serrano Migallón, Fernando. El grito de Independencia ..., p. 85.
} 
Historia, héroes y conmemoraciones como armas de lucha politica. El culto a...

fueron empleados con un sentido bélico sino para exhortar a la concordia y el apoyo al emperador.

Algunos historiadores han elaborado sus propias conclusiones respecto al dividido culto por el Héroe de Dolores en este periodo. Hay quienes coinciden en que el triunfo liberal sobre el Segundo Imperio permitió que la figura de Miguel Hidalgo tomara en definitiva su lugar como Padre de la Patria ${ }^{61}$. Sin embargo, en este artículo se pone en duda esta versión, pues como ya se explicó, Maximiliano eliminó la fiesta dedicada a Iturbide y con ello se reconocía que la única celebración de la Independencia sería la que rememoraba a Hidalgo. Se niega que el culto por el héroe de Iguala tuvo algunas atenciones, pero lo cierto es que al suprimir el festejo del 27 de septiembre quedaba estipulado que para el Imperio, al igual que para los republicanos, Hidalgo era el único Padre de la Patria. Su entronización en el santoral cívico sucedió durante el gobierno Maximiliano y no hasta su derrota en 1867.

Es importante tener en cuenta este proceso, pues en él se encuentra la explicación de porqué en México es Miguel Hidalgo -y no Agustín de Iturbide o cualquier otro personaje histórico- el héroe más reverenciado del imaginario nacional. En otras palabras, el hecho de que se considere al viejo párroco de Dolores como Padre de la Patria, no se explica por lo ocurrido durante el proceso independentista, sino en las décadas posteriores cuando distintas visiones políticas e identitarias fundaron un modelo de Estado-nación que configuró su propio relato histórico.

También es digno de resaltar que fue gracias al emperador Maximiliano que se haya pintado el cuadro de Hidalgo que terminó por convertirse en la imagen más reproducida del personaje, sentando así un canon iconográfico para representar al Padre de la Patria.

Pero la relevancia de este proceso histórico no se agota en saber quién -y cuándofue erigido como único padre de la nación mexicana, sino en lo que esto significaba en términos políticos. Aparentemente la cuestión identitaria ya había quedado solucionada (gracias a la nación imaginada por el Imperio, hubo cierto acuerdo sobre el relato histórico nacional, sus mitos fundacionales y sus héroes), pero lo que seguía en debate era si se impondría el Hidalgo reconstruido con características liberales, supuestamente republicano y precursor de la Reforma, o el Hidalgo del Segundo Imperio: defensor de la religión católica y que avalaba la monarquía. Finalmente, el triunfo de los republicanos llevó a consolidar una sola interpretación sobre el Héroe de Dolores, quien en adelante se convirtió en exclusiva fuente de legitimidad para la causa republicana y liberal.

Lo aquí abordado, permite hacer una última precisión que detrás del imaginario sobre qué fuimos y de dónde venimos como nación, existe un discurso sobre el qué queremos

\footnotetext{
${ }^{61}$ Plasencia de LA Parra, Enrique, Op. cit., p.136; Pérez Vejo, Tomás. "Hidalgo contra Iturbide: la polémica sobre el significado de la guerra de Independencia en el México anterior a la República Restaurada", en Guzmán Pérez, Moisés (coord.), Guerra e imaginarios políticos..., p. 219.
} 
ser en el presente, tanto en términos culturales, como políticos. Una práctica que poco ha cambiado en nuestro presente; por ello, sirva este estudio también para incentivar la reflexión sobre la -a veces incongruente y aberrante- manipulación política que nuestros gobiernos hacen de la historia.

\section{Bibliografía}

\section{Fuentes primarias}

\section{Archivo}

Archivo del Centro de Estudios de Historia de México, CEHM-CARSO.

\section{Publicaciones periódicas}

La sociedad, 1864.

\section{Documentación primaria impresa}

Acevedo, Esther. "Documentación de la época del Segundo Imperio", en Memoria, núm. 3, 1991.

Álbum de Hidalgo. México: IIH-UMSNH/Centro de Estudios sobre la Cultura Nicolaita, 2000.

Altamirano, Ignacio Manuel. Páginas íntimas de Ignacio Manuel Altamirano. México: Gobierno del Estado de Guerrero, 1996.

Hernández y Dávalos, J. E. Colección de documentos para la historia de la guerra de Independencia de México de 1808 a 1821, t. II. Liechtenstein: Kraus Reprint, 1968.

Prieto, Guillermo. Atentamente... Guillermo Prieto. México: Promexa Editores, 1979.

Ramírez, Ignacio. Obras Completas de Ignacio Ramírez (El Nigromante). México: Centro de Investigaciones Científicas Jorge T. Tamayo, 1987.

Serrano Migallón, Fernando. La Independencia vista por la Reforma. México: CONACULTA, 2009.

\section{Fuentes Secundarias}

\section{Libros}

Anderson, Benedict. Comunidades imaginadas. Reflexiones sobre el origen y difusión del nacionalismo. México: FCE, 1993.

Beezley, William H. La identidad nacional mexicana. La memoria, la insinuación y la cultura popular en el siglo XIX. México: COLEF/COLSAN/COLMICH, 2008. 
Historia, héroes y conmemoraciones como armas de lucha política. El culto a...

Bobbio, Norberto y Viroli, Maurizio. Diálogo en torno a la república. México: Tusquets, 2002.

Brading, David. Mito y profecía en la historia. México: FCE, 2010.

Breully, John. Nacionalismo y Estado. Barcelona: Ediciones Pomares-Corredor, 1990.

Burke, Peter. Formas de historia cultural. Madrid: Alianza Editorial, 2011.

Cañedo Gamboa, Sergio A. Los festejos septembrinos en San Luis Potosí. Protocolo, discurso y tansformaciones, 1824-1847. México: El Colegio de San Luis, 2001.

Crespo, José Antonio. Contra la historia oficial. Madrid: Debolsillo, 2010.

Hobsbawm, Eric. Naciones y nacionalismos desde 1780. Barcelona: Grijalbo, 1991.

Gellner, Ernest. Nacionalismo. Barcelona: Ediciones Destino, 1997.

Gellner, Ernest. Naciones y nacionalismo. México: CONACULTA/Alianza Editorial, 1991.

Mallón, Florencia. Campesinos y nación. La construcción de México y Perú poscoloniales. México: CIESAS/COMICH/COLSAN, 2003.

Moreno Elizondo, José Elizondo. El nacimiento de la tragedia. Criminalidad, desorden público y protesta popular en las fiestas de Independencia. Ciudad de México 18871900. México: Instituto de Investigaciones Dr. José María Luis Mora, 2015.

Pani, Erika. Para mexicanizar el Segundo Imperio. El imaginario político de los imperialistas. México: El Colegio de México/Instituto de investigaciones Dr. José María Luis Mora, 2001.

Pérez Vejo, Tomás. España en el debate público mexicano, 1836-1867. Aportaciones para una historia de la nación. México: El Colegio de México/ENAH/INAH), 2008.

Pérez Vejo, Tomás. Nación, identidad nacional y otros mitos nacionalistas. Oviedo: Ediciones Nobel 1999.

Plasencia de la Parra, Enrique. Independencia y nacionalismo a la luz del discurso conmemorativo (1825-1867). México: CONACULTA, 1991.

Rojas, Reinaldo. Venezuela: Fiesta, imaginario político y nación. San Felipe, Yaracuy: Universidad Nacional Experimental del Yaracuy, 2011.

Serrano Migallón, Fernando. El grito de Independencia. Historia de una pasión nacional. México: Porrúa, 1995. 
(Sin datos). Tres siglos de filatelia en México. México: AMEXFIL, 2006.

\section{Capítulos de libros}

Barrón, Luis. "Republicanismo, liberalismo y conflicto ideológico en la primera mitad del siglo XIX en América Latina”, en Aguilar, José Antonio y Rojas, Rafael (coords.), El republicanismo en Hispanoamérica. Ensayos de historia intelectual y politica. México: FCE/CIDE, 2002.

Cannadine, David. "Contexto, representación y significado del ritual: la monarquía británica y la ‘invención de la tradición', 1820-1977”, en Hobsbawm, Eric y Ranger, Terence (coords.), La invención de la tradición. Barcelona: Crítica, 2002.

Chust, Manuel y Mínguez, Víctor. "Presentación”, en Chust, Manuel y Mínguez, Víctor (eds.), La construcción del héroe en España y México (1789-1847). Valencia: Universitat de Valencia, 2003.

Costeloe, Michael. "The junta patriótica and the celebration of Independence in Mexico city, 1825-1855", en Beezley H., William y Lorey, David E. (eds.), iViva Mexico! ;Viva la Independencia! Celebrations of september 16. Wilmington: Scholary Resources, 2001.

Falcón, Romana. "Los trozos de la nación. Retos en el estudio de la formación de la nación mexicana", en Oikión Solano, Verónica (ed.), Historia, nación y región. Zamora: El Colegio de Michoacán, 2007.

Garciadiego, Javier. "La política de la historia: Las conmemoraciones de 2010", en Pani, Erika y Rodríguez Kuri, Ariel (coords.), Centenarios. Conmemoraciones e historia oficial. México: El Colegio de México, 2012.

Gutiérrez Viñuales, Rodrigo. "Construyendo las identidades nacionales. Próceres e imaginario histórico en Sudamérica (siglo XIX)", en Chust, Manuel y Mínguez, Víctor (eds.), La construcción del héroe en España y México (1789-1847). Valencia: Universitat de Valencia, 2003.

Guzmán Pérez, Moisés. “Adiós a Pelayo. La invención del héroe americano y la ruptura con la identidad hispana”, en Sánchez Andrés, Agustín; Pérez Vejo, Tomás y Landavazo, Marco Antonio (coords.), Imágenes e imaginarios sobre España en México. Siglos XIX y XX. México: Porrúa/CONACYT/IIH-UMSNH, 2007.

Hobsbawm, Eric. "Introducción: la invención de la tradición”, en Hobsbawm, Eric y Ranger, Terence (coords.), La invención de la tradición. Barcelona: Crítica, 2002.

Lacy, Elaine C. “The 1921 Centennial celebration of Mexico's Independence. State building and popular negotiation”, en Beezley H., William y Lorey, David E. (eds.), ¡Viva Mexico! ¡Viva la Independencia! Celebrations of september 16. Wilmington: Scholary Resources, 2001. 
Historia, héroes y conmemoraciones como armas de lucha politica. El culto a...

Landavazo, Marco Antonio. "Hidalgo: ideología e historia", en Velarde, Sofía y Dávila, Carmen Alicia (coords.), Miguel Hidalgo en la historia y el arte. Morelia: Gobierno del Estado de Michoacán, 2004.

Mínguez, Víctor. "Héroes clásicos y reyes héroes en el antiguo régimen", en Chust, Manuel y Mínguez, Víctor (eds.), La construcción del héroe en España y México (1789-1847). Valencia: Universitat de Valencia, 2003.

Moya Gutiérrez, Arnaldo. "Los festejos cívicos septembrinos durante el Porfiriato, 18771910”, en Agostini, Claudia y Speckman Elisa (eds.), Modernidad, tradición y alteridad. La ciudad de México en el cambio de siglo (XIX-XX). México: IIH-UNAM, 2001.

O’Gorman, Edmundo. "Hidalgo en la historia”, en Terán, Marta y Páez, Norma, Miguel Hidalgo: ensayos sobre el mito y el hombre (1953-2003). México: CONACULTA/ INAH, 2004.

Pani, Erika. "Cultura nacional, cannon español”, en Lida, Clara E., España y el Imperio de Maximiliano. México: El Colegio de México, 1999.

Pérez Vejo, Tomás. "Hidalgo contra Iturbide: la polémica sobre el significado de la guerra de Independencia en el México anterior a la República Restaurada”, en Guzmán Pérez, Moisés (coord.), Guerra e imaginarios políticos en la época de las Independencias. Morelia: IIH-UMSNH, 2007.

Ramírez, Fausto. "Hidalgo en su estudio, la ardua construcción de la imagen del Pater Patriae mexicano", en Chust, Manuel y Mínguez, Víctor (eds.), La construcción del héroe en España y México (1789-1848). Valencia: Universitat De Valencia, 2003.

Ramírez, Fausto. "Miguel Hidalgo: de sacerdote a patriarca", en Azcárate Esquinca, Bernardo (coord.), El éxodo mexicano, los héroes en la mirada del arte (México: UNAM/MUNAL, 2010, pp. 230-285.

Rodríguez Moya, Inmaculada. "La galería de héroes de Maximiliano: hacia una reconciliación del imaginario mexicano", en Mínguez, Víctor y Chut, Manuel (eds.), El imperio sublevado. Madrid: CSIC, 2004.

Rodríguez Piña, Javier. "Conservatives contest the meaning of the Independence, 1846-1855”, en Beezley H., William y Lorey, David E. (eds.), ¡Viva Mexico! ¡Viva la independencia! Celebrations of september 16. Wilmington: Scholary Resources, 2001.

Santos, Ana. "El 50 aniversario de la Revolución mexicana: entre la continuidad y el agotamiento de la revolución permanente", en Pani, Erika y Rodríguez Kuri, Ariel (coords.), Centenarios. Conmemoraciones e historia oficial. México: El Colegio de México, 2012. 
Vaughan, Mary Kay. "The construction of the patriotic festival in Tecamachalco, Puebla, 1900-1946", en Beezley, H. William; English Martin, Cheryl y French, William E. (eds), Rituals of rule, rituals of resistence. Public celebrations and popular culture in Mexico. Wilmington: Scholary Resources, 1999.

Volvelle, Michel. "La Revolución francesa: ¿Matriz de la heroización moderna?”, en Chust, Manuel y Mínguez, Víctor (eds.), La construcción del héroe en España y México (1789-1847). Valencia: Universitat de Valencia, 2003.

Zárate Toscano, Verónica, "San Angel as the site of national festivals in the 1860's", en Beezley, William H., y Lorey, David E. (eds.), iViva Mexico! ;Viva la Independencia! Celebrations of september 16. Wilmington: Scholary Resources, 2001 .

\section{Artículos en revistas}

Acevedo, Esther. "Las imágenes de la historia (1863-1867). Memoria y destrucción”, en Memoria, núm. 3, 1991.

Earle, Rebeca. "Padres de la patria and the ancestral past: conmemorations of independeces in nineteenth-century Spanish America", en Journal of Latin American Studies, núm. 34, 2002.

Earle, Rebeca. "Sobre héroes y tumbas: símbolos nacionales en la Hispanoamérica del siglo XIX", en Bicentenario. Revista de historia de Chile y América, vol. VII, núm. 1, 2008.

Florescano, Enrique. "Notas sobre las relaciones entre memoria y nación en la historiografía mexicana”, en Historia Mexicana, vol. LIII, núm. 2, 2003.

González Salinas, Omar Fabián. "Fiesta cívica y culto al 'Padre de la Patria' en el Estado revolucionario, 1910-1940”, en Secuencia. Revista de historia y ciencias sociales, núm. 93, 2015.

González Salinas, Omar Fabián. "La primera construcción mítica en torno a Miguel Hidalgo", en Revista de El Colegio de San Luis, vol. IV, núm. 8, 2015.

Guerra, François-Xavier. "La nación moderna: Nueva legitimidad y viejas identidades”, en Tzintuzn. Revista de estudios históricos, núm. 36, 2002.

Nora, Pierre. "La aventura de Les lieux de mémoire", en Ayer. Revista de historia contemporánea, núm. 32, 1998.

Pani, Erika. "El proyecto de Estado de Maximiliano a través de la vida cortesana y del ceremonial público”, en Historia Mexicana, vol. XLV, núm. 2, 1995. 
Historia, héroes y conmemoraciones como armas de lucha politica. El culto a...

Pani, Érika. “'Verdaderas figuras de Cooper' o ¿'Pobres inditos infelices'? La política indigenista de Maximiliano", en Historia Mexicana, vol. XLVII, núm. 3, 1998.

Pérez Vejo, Tomás. "La construcción de naciones como problema historiográfico: el caso del mundo hispánico”, en Historia Mexicana, vol. LIII, núm. 2, 2003.

Ríos Gordillo, Carlos Alberto. "La memoria asediada. La disputa por el presente en la conmemoración del bicentenario", en Secuencia. Revista de historia y ciencias sociales, núm. 87, 2013.

Uzeta, Jorge. "Los usos de Hidalgo", en Relaciones. Estudios de historia y sociedad, vol. XXVII, núm. 106, 2006. 